\title{
Yield Prediction of Sugar Beet through Combined Use of Satellite Data and Meteorological Data
}

\author{
Chiharu Hongo (Corresponding author) \\ Center for Environmental Remote Sensing, Chiba University \\ 1-33 Yayoi, Inage, Chiba 263-8522, Japan \\ Tel: 81-43-290-3859Ｅ-mail: hongo@faculty.chiba-u.jp \\ Katsuhisa Niwa \\ Zukosha co Ltd., 17, Kita1, Nisi18, Obihiro, Hokkaido 080-0048, Japan \\ Tel: 81-155-33-4491 E-mail: niwa@zukosha.co.jp
}

Received: December 9, 2011

Accepted: December 31, 2011

Online Published: February 2, 2012

doi: $10.5539 /$ jas.v4n4p251

URL: http://dx.doi.org/10.5539/jas.v4n4p251

This study was funded by the Ministry of Agriculture, Forestry and Fisheries, Japan as part of Research on Advanced Technologies in Agriculture, Forestry and Fisheries (assignment number: 18083).

\begin{abstract}
This study was carried out for the following two purposes through analysis of satellite data and meteorological data. One is to assess the feasibility of developing an efficient cultivation support system for effective reduction of costs relating to sugar beet cultivation. The other is to predict the root yield before the harvesting season.

The cumulative temperature, cumulative precipitation and cumulative solar radiation from the end of April to the middle of July were selected as the predictors of the root yield prediction formula. The predictive error was $3.8 \mathrm{t} / \mathrm{ha}$, that was a result calculated by the farmers group, after weighted to the predicted root yield using NDVI. The results suggest that it is possible to predict the root yield before three months of the harvesting season. For providing such results to sugar companies in much earlier before the harvesting, the efficiency of sugar beet collection and sugar production will increase substantially.
\end{abstract}

Keywords: Sugar beet, Yield prediction, Remote sensing, Meteorological data

\section{Introduction}

In Japan, the sugar beet is cultivated only in Hokkaido, the northern island. An area of the sugar beet cultivation in Tokachi District of Hokkaido is 30,000 ha, which is equal to about $45 \%$ of the total national production area (MAFF 2006). Because the sugar beet is suited to cool weather conditions, it is one of important rotation crops in Hokkaido.

The production of beet sugar in Hokkaido is about 640,000 tons, which is 3/4 of the total national production (MAFF 2006). The Japanese government is now carrying out new policy; "New policy on sugar beet crops and other sweet resources", which is to reduce the costs of the production and manufacturing processes.

It is expected that reduction of amount of fertilizers to be used, which is $25 \%$ of the total production cost, can contribute much to reduction of the total costs of agricultural production. Also, the sugar concentration in the root will increase upon optimization of the amount of nitrogen fertilizer. Furthermore, through appropriate scheduling of the collection of sugar materials using the data to predict the root yield before the harvesting, the costs of fuels to be used for transportation is expected to be reduced. These are other very useful effects utilizing the prediction method of the root yield.

To realize the above benefits, the root yield data of "individual fields" is necessary, but at present only the yield data of "each farmer" is available. It is time-consuming process to collect and unify such data for practical use, thus it is highly desirable to develop a new method for determining the crop status and the yield data of individual fields. Remote sensing and Geographic Information Systems (GIS) may provide technologies needed 
for farmers to maximize the economic and environmental benefits of the precision farming (Santhosh et al. 2003). Under these circumstances, this study on "Development of an efficient sugar beet cultivation support system using agricultural spatial information" was started with the aim at constructing a new method to collect field observation data using the remote sensing, GIS and meteorological data. The objective of this study is to assess the potential of developing an efficient sugar beet cultivation support system that can reduce the costs of beet crop cultivation, sugar production and sugar material distribution with use of the agricultural spatial information.

In previous research works in an earlier phase of agricultural remote sensing research in Japan, the root yield of sugar beet was estimated by the reflectance of red wavelength $(650 \mathrm{~nm})$ and that of near-infrared wavelength $(850 \mathrm{~nm})$ of cultivated sugar beet grown using various amounts of different fertilizer (Saito et al. 1991). In addition, it was reported that $\mathrm{K}$-value derived from the reflectance at wavelengths of $650 \mathrm{~nm}$ and $850 \mathrm{mn}$ was a suitable index for estimating the root yield in August (Saito et al. 1991). The possibility of nutritional diagnosis for checking nitrogen and phosphorus deficiency was also reported (Genya et al. 1991). In the 1990s, a study on estimation of the sugar concentration in the root and the root yield using Landsat TM data (Okano et al. 1994) and a study on estimation of the amount of nitrogen absorption using Landsat TM data were carried out (Okano et al. 1995). These research results indicated that the remote sensing data was useful for assessing the quantity and quality of individual fields and also for improving the productivity of sugar beet with the appropriate application of nitrogen fertilizer. Through the analysis of sugar beet damaged by cold and wet weather using Landsat TM data and soil data, a region with a relatively low root yield was shown to be related to the poor drainage of the soil, the existence of compact subsoil and the lack of a gravel layer (Asaka 1993). For use of crop models for large areas to predict crop production, the SUCROS sugar beet model and remotely sensed data were applied to estimate the root yield (Guerif et al. 1998, Launay et al. 2005). In our previous papers, we reported that the expected root yield could be estimated by analyzing remote sensing data acquired in summer, because there was positive correlation between the total biomass of the beet top in July and the root yield and sugar yield in the harvesting season (Hongo et al. 2006a, 2006b, 2008).

Until now, data for predictors in the conventional estimation formula has been collected at the harvesting season, and the absolute yield value cannot be derived before the harvesting even if remote sensing data obtained in July is analyzed. The root yield observation data in the harvesting season is necessary to determine the absolute yield value. This means that we have to wait until October to assess the yield. In this study, to predict the root yield of sugar beet three months before the harvesting, the analysis of satellite data and meteorological data was carried out. A new method is reported for prediction of the root yield from the data on cumulative temperature, cumulative precipitation, cumulative solar radiation and NDVI.

\section{Methodology}

\subsection{Study Site}

This study was conducted in the town near Memuro located in the middle west of the Tokachi plain, Hokkaido, Japan (longitude $143.1^{\circ} \mathrm{E}$, latitude $42.9^{\circ} \mathrm{N}$ ) (Figure 1). The area of the test site for this study is $22.6 \mathrm{~km}$ from east to west and $35.4 \mathrm{~km}$ from north to south, in which large-scale agricultural management is performed. The area surrounding Memuro is mostly covered with farmland and forest, which is equal to about $42 \%$ and $40 \%$ of the area, respectively. The cultivation area around Memuro is $19,720 \mathrm{ha}$, and the average cultivation area per farmer is $28 \mathrm{ha}$. The cultivation season of Memuro is from April to October. The major crops are sugar beet, potatoes, wheat, sweet corn and legumes, and the planting acreage of each crop is $20.9 \%, 19.8 \%, 36.0 \%, 5.6 \%$, and $14.2 \%$, respectively. The rotation of crops is performed by the combination of major crops with vegetables at three or four-year interval. In this study, sugar beet was selected to analyze the root yield. The acreage of sugar beet cultivation is 3,505ha in Memuro, and the average cultivation area of sugar beet per farmer is 6.9 ha (MAFF 2007).

Memuro has inland climate, and the largest number of fine weather days in Japan is recorded here. The yearly average temperature is $6^{\circ} \mathrm{C}$, and the yearly range of temperature is very large, in summer temperature can reach over $30^{\circ} \mathrm{C}$, while in winter below $-20^{\circ} \mathrm{C}$.

The altitude of Memuro ranges from $45 \mathrm{~m}$ to $300 \mathrm{~m}$. The test site can be divided into three geographical types: lowland, low, middle and high terraces (Kikuchi 1981) (Figure2). The main parent materials constituting each geographical type are as follows: the alluvial deposits in the lowland, the low terrace with volcanic ash and alluvial deposit, and the middle to high terraces with volcanic ash (Koji Kikuchi 1981). These soil types are classified using the soil classification of FAO into Hapic Fluvisols (alluvial deposit areas), Mollic Fluvisols (volcanic ash / alluvial deposit areas) and Andic Gleysols and Mollic Andisols (volcanic ash areas). 


\subsection{Root Yield Data and Ground Observation Data}

Two types of root yield data were collected to predict the root yield of sugar beet. One is the annual average root yield in Memuro from 1990 to 2007, which was compiled by Hokkaido Government Tokachi Subprefectural Office. The data from 1990 to 2005 was used to construct a formula to predict root yield, and the data of 2006 and 2007 was used to validate the accuracy of the predicted root yield. The other yield data is the annual average root yield of farmers' groups. In Memuro, there are 121 farmers' groups growing sugar beet. This data was used to validate the accuracy of the predicted root yield after calculating the predicted yield value in proportion to the NDVI value.

Moreover, sugar beet field observation data was prepared to analyze the relationship between beet tops and root yield. To measure plant height, leaf color (SPAD: Soil \& Plant Analyzer Development), root yield and sugar concentration, investigation points were set at 56 different locations in each area of 3 rows $\times 7$ plants. The field survey was performed from June to October in 2006 and 2007.

\subsection{Meteorological Data}

Data on cumulative temperature, cumulative rainfall and cumulative solar radiation from the end of April to the middle of July was collected in both Obihiro meteorological observatory and Memuro observation site. The data was added to the table on the GIS of the farmers' groups.

\subsection{Satellite Data}

Spot5 satellite (HRG-X) data was acquired on July 27, 2006 and July 27, 2007. In the satellite imagery, there are 4 bands, which include as the observation wavelengths, the green band $(500-590 \mathrm{~nm})$, red band $(610-680 \mathrm{~nm})$, near infrared band $(780-890 \mathrm{~nm})$ and short-wavelength infrared band $(1580-1750 \mathrm{~nm})$, and the imagery has both $10 \mathrm{~m}$ image resolution for the visible bands and near-infrared band and $20 \mathrm{~m}$ image resolution for the short-wavelength infrared band.

NDVI stands for "Normalized Difference Vegetation Index" and is calculated using the following formula:

$\mathrm{NDVI}=(\mathrm{NIR}-\mathrm{R}) /(\mathrm{NIR}+\mathrm{R})$

where $\mathrm{R}$ is radiance of red wavelength, NIR is radiance of near-infrared wavelength.

\subsection{GIS Data}

GIS data of 2006 and 2007 was used to identify sugar beet fields from the satellite data, and the GIS of the farmers' groups was prepared to unify various yield data, meteorological data and satellite data.

\subsection{Procedure}

The procedure for predicting the root yield is described in Figure 3.

To derive the root yield prediction equation, the multiple linear regression analysis was executed using the data on cumulative temperature, cumulative rainfall and cumulative solar radiation from the end of April to the middle of July from 1990 to 2005. The average root yields of Memuro in 2006 and 2007 were predicted using the yield prediction equation.

Secondly, the satellite data and GIS data were rectified with use of a geographic map drawn at a scale of 1 to 25,000 though the nearest neighbor resampling algorithm using the selected ground control points. A shape file of the sugar beet fields was created from the GIS data and overlaid on the satellite data to extract the sugar beet fields. The digital values of sugar beet fields derived from the satellite data were converted to the surface radiance values, and the majority value of the NDVI was calculated from the radiance values of all sugar beet fields in Memuro.

The predicted yields obtained from the meteorological data and the majority value of NDVI are presumed to be equal, and the NDVI values of whole sugar beet fields were transformed into absolute root yield value after calculating the predicted yield value in proportion to the NDVI value.

Finally, to validate the root yield prediction results of 2006 and 2007, the predicted root yields of the farmers' groups were compared with the observed root yields by calculating RMSE (root mean square error). The definition of RMSE is as follows:

$$
R M S E=\sqrt{\frac{1}{n} \sum_{i}\left(P_{i}-O_{i}\right)^{2}}
$$


where $\mathrm{P}$ is the predicted root yield, $\mathrm{O}$ is the observed root yield and $\mathrm{n}$ is number of the data

\section{Results and Discussion}

\subsection{Relationship between the Growth Data of Sugar Beet and the Satellite Data}

The relationship between SPAD $\times$ plant height and the root yield was investigated. There is positive correlation between [SPAD $\times$ plant height] on July 12 and the root yield on October 4, 2007 (Figure 4). The coefficient of determination is 0.64 . The value of [SPAD $\times$ plant height] is applied to a diagnosis index indicating the status of crop nutrition and crop growth where a high value indicates a rich amount of nitrogen nutrients and a large amount of biomass of the sugar beet crop. The results show that sugar beet with a larger amount of leaf and stem in July has higher root yield in the harvesting season, and it is also suggested that the root yield in the harvesting season is determined by the growth status of beet tops in July. Moreover, there is positive correlation between [SPAD $\times$ plant height] and NDVI on July 27, $2007\left(\mathrm{r}^{2}=0.6\right)$ (Figure 5). Through these results, it will be possible to estimate the root yield of sugar beet about three months before the harvesting season.

\subsection{Prediction of Root Yield of Sugar Beet in Memuro Using Meteorological Data}

In previous research, it was reported that the root yield and sugar yield could be estimated using solar radiation, temperature and precipitation data from transplantation stage to the middle growth stage (Hongo et al. 2006b)). Clevers(1997) suggested that the leaf area index, the amount of absorbed photosynthetically active radiation and the optical remote sensing data were suitable predictors for the estimation of actual yield of sugar beet. Shresthaa et al. (2010) reported that a response of sugar beet to water stress was stronger than 30 years ago. From this point, it can be considered that the photosynthetic rate (sugar production) is strongly affected by solar radiation and also that the rate of expansion of leaf area is affected by temperature. In addition, the sugar beet yield in Memuro depends strongly on the water content in soil particularly.

Therefore, in this study, the multiple regression analysis was executed to predict the root yield in the harvesting season using cumulative temperature, cumulative rainfall and cumulative solar radiation from the end of April to the middle of July from 1990 to 2005 . The root prediction formula derived from these predictors is as follows:

$$
\mathrm{RY}=0.043675 \mathrm{R}+0.02783 \mathrm{~T}-1.09513 \mathrm{P}-39.634\left(\mathrm{r}^{2}=0.87^{* *}\right)
$$

where $\mathrm{RY}$ is the root yield, $\mathrm{R}$ is the cumulative solar radiation, $\mathrm{T}$ is the cumulative temperature and $\mathrm{P}$ is the cumulative precipitation.

The coefficient of determination of the prediction formula is 0.87 , which is significant at the $1 \%$ level. RMSE is $3.2 \mathrm{t} / \mathrm{ha}$, which is calculated from the predicted root yield and observed root yield. The predicted values plotted against the observed values are scattered around the 1:1 line. The root yields of 2006 and 2007 were predicted using the prediction formula. The prediction yield of 2006 is $58.64 \mathrm{t} / \mathrm{ha}$, which is $0.4 \%$ larger than the actual yield of 58.04t/ha of Ministry of Agriculture, Forestry and Fisheries (MAFF) statistical data. Furthermore, the prediction yield of 2007 is $72.04 \mathrm{t} / \mathrm{ha}$, which is $2.1 \%$ larger than the actual yield of $70.54 \mathrm{t} / \mathrm{ha}$ in the MAFF statistical data.

\subsection{Prediction of Root Yield of Individual Sugar Beet Fields Using Meteorological and Satellite Data}

The predicted root yields of 2006 and 2007 derived through the prediction formula described in section3.2 corresponded closely to the ground observation values of MAFF. We then conducted the prediction of root yield for individual fields and farmers' groups before the harvesting using the new method on the basis of spot satellite data acquired on July 27, 2006 and July 27, 2007 and the predicted root yield from meteorological data.

In our previous research, we reported that there was a positive correlation between the root yield at the harvesting season and the amount of beet top in July and also that it was possible to estimate the root yield by analyzing the SPOT5 satellite data acquired in July (Hongo et al. 2006a; 2006b; 2008).

However, the absolute root yield value cannot be obtained before the harvesting season even if the satellite data in July is applied to this prediction approach because it is necessary to know the ground observation root yield data in October, which is input into the prediction formula to derive the absolute root yield value. Thus, we focused on the relationship between the beet top biomass and NDVI in July and the root yield in October, and the absolute root yield value was derived using the following prediction procedure.

The root yield predicted using the formula described in section 3.2 was replaced by the majority NDVI value of the beet fields cultivated in the study site. The predicted average root yield was converted to the root yield of individual sugar beet fields in proportion to the NDVI value. Finally, the average root yield of each farmers' group was calculated from the yields of individual sugar beet fields. 
The prediction accuracy for 2006 is shown in Figure 6, for which RMSE is 6.1t/ha and the correlation coefficient between the predicted values and the observed values is 0.54 . The yields of farmers' groups with extremely small cultivation acreage are relatively overestimated. The result suggests that the accuracy of the prediction can be improved in future by analyzing the weighted average. The scatter graph in Figure 7 shows the relationship between the prediction root yield and the observed root yield in 2007. The ground observed root yield data of 2007 is not the farmers' group data of MAFF. The data was collected from the observation points in the farmers' fields, each of which consisted of three rows of 7 plants. The RMSE of the predicted value relative to the observed root yield is $4.8 \mathrm{t} / \mathrm{ha}$, corresponding to an error of about $6.8 \%$ against the observed value of $70.54 \mathrm{t} / \mathrm{ha}$. However, the RMS error of the predicted value is $3.8 \mathrm{t} / \mathrm{ha}$ after eliminating the fields with the brown lowland soils.

The productivity of the root yield in Memuro has been decreasing since 1990 (Niwa et al. 2008). A characteristic of the brown lowland soils is the shallow effective soil layer (Kikuchi 1981). The reason for the decrease in the root yield productivity may be attributed to the reduced growth of the beet top biomass caused by low water content in the soil due to low cumulative precipitation. Niwa et al. (2006) reported the reduction of root yield in the brown lowland soils in Tokachi District; their research results show that the formation of a tillage pan caused by heavy agricultural machinery affects the beet top and the root yield productivity. In addition, the low productivity phenomenon remarkably appears under heavy precipitation conditions. Considering these results, the development of a formula for predicting the root yield for each soil type can contribute to improvement of the prediction accuracy.

Figure 8 shows a prediction map of root yield for individual fields created using the average root yield and NDVI value. A map of individual root yields averaged by each farmers' group, divided into 5 levels according to the yield, is shown in Figure 9.

This root yield map of farmers' groups obtained from meteorological and satellite data is good agreement with the map of root yield productivity currently utilized. The results suggest that it is possible to predict the root yield three months before the harvesting season. For providing such results to sugar companies much earlier before the harvesting, the efficiency of sugar beet collection and sugar production will be increased.

\section{Conclusion}

In this study, analysis of satellite data and meteorological data was carried out to assess the feasibility of development of an efficient sugar beet cultivation support system to effectively reduce the costs of beet cultivation, beet collection and sugar production using agricultural spatial information, and also to predict the root yield of sugar beet three months before the harvesting season.

The results show that it is possible to predict the root yield with high accuracy using the meteorological data. Also, the root yield of individual fields and farmers' groups can be predicted using the meteorological data and the NDVI value obtained from satellite data. Most of methods for yield estimation reported in previous research involve estimation equations using digital satellite data and ground observation data. In this study, we have constructed a new yield prediction method where the NDVI values of whole sugar beet fields are replaced into the absolute root yield value after predicting the average root yield of town scale with use of meteorological data.

By providing such results to sugar companies much earlier before the harvesting, the efficiency of sugar beet collection and sugar production is expected to increase substantially, that will lead to more economic and environmental benefits. Our results show that the application of agricultural spatial information is extremely promising for estimating the sugar beet yield. We believe that the practical use of such method will be realized in the near future by tackling the remaining problems.

\section{Acknowledgements}

The authors would like to express our deepest gratitude to Dr. Roji Samejima, Dr. Ryutaro Yamada, Dr. Masato Kuwahara, Dr. Jun Yokobri, Dr. Akira Nishimune and Mr. Eisaku Tamura whose comments and suggestions made enormous contribution to our research. We would also like to acknowledge the Agricultural Cooperative Association of Memuro, Nippon Beet Sugar Manufacturing Co.Ltd., and Hokkaido Sugar Beet Association for providing yield data and GIS data. A patent has been applied for part of the research results.

\section{References}

Chiharu Okano, Michikazu Fukuhara, Akira Nishimune, Noritsugu Shimada \& Yukio Watanabe. (1994). Estimation of Sugar rate, root weight and sales of sugar beet by Landsat TM data at harvesting time. Journal of the Japanese Agricultural System Society, 137-144, vol. 10(1). 
Chiharu Okano, Michikazu Fukuhara, Akira Nishimune, Masashi Hayasaka \& Noritsugu Shimada. (1995). Estimation of nitrogen absorption amount of sugar beet by Landsat TM data. Journal of the Japanese Agricultural System Society, 11-20, vol.11(2).

Chiharu Hongo, Takanori Suzuki, Yukinobu Hiramitsu, \& Takashi Miyamoto. (2006a). Development of an efficient sugar beet cultivation support system using the agricultural spatial information -Part1-Growth analysis of sugar beet using a satellite image and GIS, Proceedings of the 4lth autumn conference of the remote sensing society of Japan, 41, 291-292.

Chiharu Hongo, Katsuhisa Niwa, Ryutaro Yamada, Ryoji Samejima, Yashishi Hiramitsu, Masato Kuwahara, \& Takanori Suzuki. (2006b). Development of an efficient sugar beet cultivation support system using the agricultural spatial information -Part2-Estimation of root yield and growth analysis based on soil type, Proceedings of the 42th spring conference of the remote sensing society of Japan, 42, 155-156.

Chiharu Hongo, Katsuhisa Niwa, Jun Yokobori, Ryutaro Yamada, \& Masato Kuwahara. (2008). Development of an efficient sugar beet cultivation support system using the agricultural spatial information -Part3-Prediction of root yield using meteorological data and satellite data, Proceedings of the 45th autumn conference of the remote sensing society of Japan, 45, 115-116.

Daiji Asaka. (1995). The use of LANDSAT TM data for estimating the interaction of sugar beet yields damaged by cool and wet weather in 1993 with soil properties. Soil Physical Conditions and Plant Growth, Japan, No.72, 27-37.

Genya Saito \& Michikazu Fukuhara. (1982). Spectral reflectance factor in sugar beet growth and yield estimation, Research bulletin of the Hokkaido National Agricultural Experiment Station, No.139, 39-54.

Genya Saito, Yoshizumi Yasuda \& Yasufumi Emori. (1991). Estimating Sugar beet Yields by Spectral Radiometer. Asean Pacific Trmote Sensing Journal, 4(1), 109-116.

Koji Kikuchi. (1981). Interpretative classification of soil in the Tokachi district, and their mapping and practical application for soil improvement, Report Hokkaido Prefect. Agric. Exp. Stn., 34, 1-118.

J.G.P.W Clevers. (1997). A simplified approach for yield prediction of sugar beet based on optical remote sensing data. Remote Sensing of Environment, Vol.61(2), 221-228. http://dx.doi.org/10.1016/S0034-4257(97)00004-7

Katsuhisa Niwa, Nobutaka Seino, Jun Yokobori, Koji Kikuchi \& Chiharu Hongo. (2008). Effect of soil type on the time-course of changes in sugar beet (Beta vulgaris L.) productivity in Tokachi district, Hokkaido, Japan, Soil Science and Plant Nutrition, 54,928-937. http://dx.doi.org/10.1111/j.1747-0765.2008.00322.x

M. Guérif, \& C. Duke1. (1998). Calibration of the SUCROS emergence and early growth module for sugar beet using optical remote sensing data assimilation. European Journal of Agronomy, Vol.9(2-3), 127-136. http://dx.doi.org/10.1016/S1161-0301(98)00031-8

Marie Launay, \& Martine Guerif. (2005). Assimilating remote sensing data into a crop model to improve predictive performance for spatial applications Agriculture. Ecosystems \& Environment, Vol.111(1-4), 321-339. http://dx.doi.org/10.1016/j.agee.2005.06.005

Ministry of Agriculture, Forestry \& Fisheries, Japan. (2006). The present state of and issue on the policy of sugar and sweetness-resource crops.

URL:http://www.maff.go.jp/www/counsil/counsil_cont/kanbou/kanmi/h17-1/siryou3.pdf

Ministry of Agriculture, Forestry and Fisheries, Japan. (2007). The Statistical Year Book (2005-2006) of MAFF, Hokkaido, Norin Tokei Kyokai, Sapporo.

Nirman Shresthaa, Sam Geertsa, Dirk Raesa, Stefaan Horemansb, Sarah Soentjensb, Fabienne Maupasc, \& Philippe Clouet. (2010). Yield response of sugar beets to water stress under Western European conditions. Agricultural Water Management, Vol.97(2), 346-350. http://dx.doi.org/10.1016/j.agwat.2009.10.005

Santhosh K Seelan, Soizik Laguette, Grant M Casady, \& George A Seielstad. (2003). Remote sensing applications for precision agriculture: A learning community approach, Remote Sensing of Environment, Vol.88(1-2), 157-169. http://dx.doi.org/10.1016/j.rse.2003.04.007 


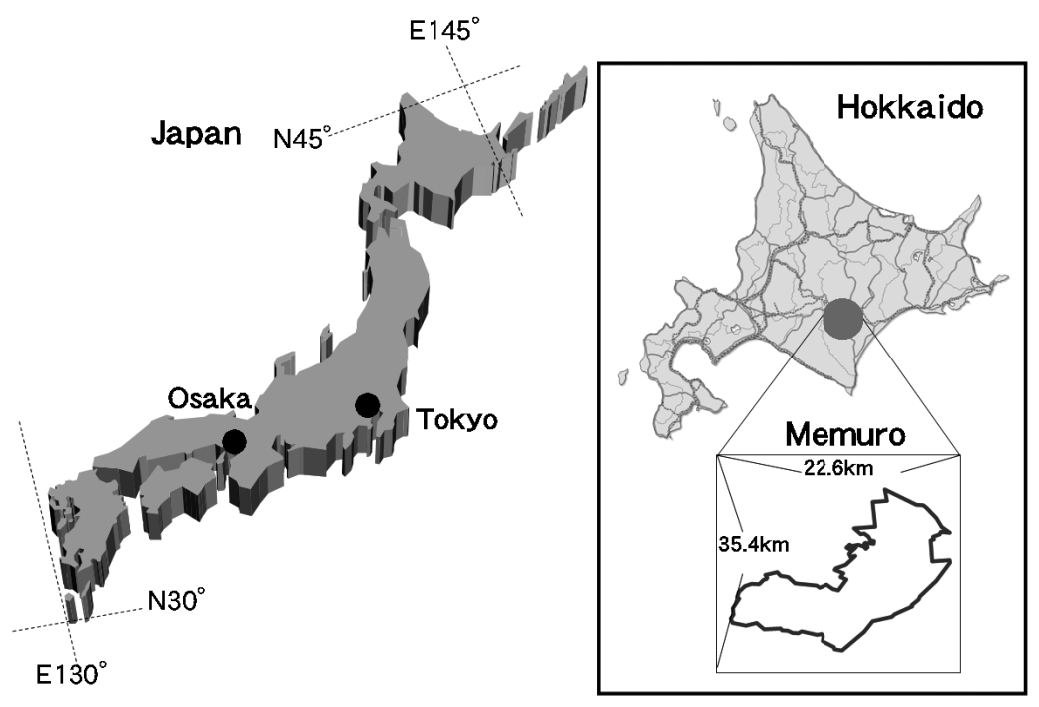

Figure 1. Study site

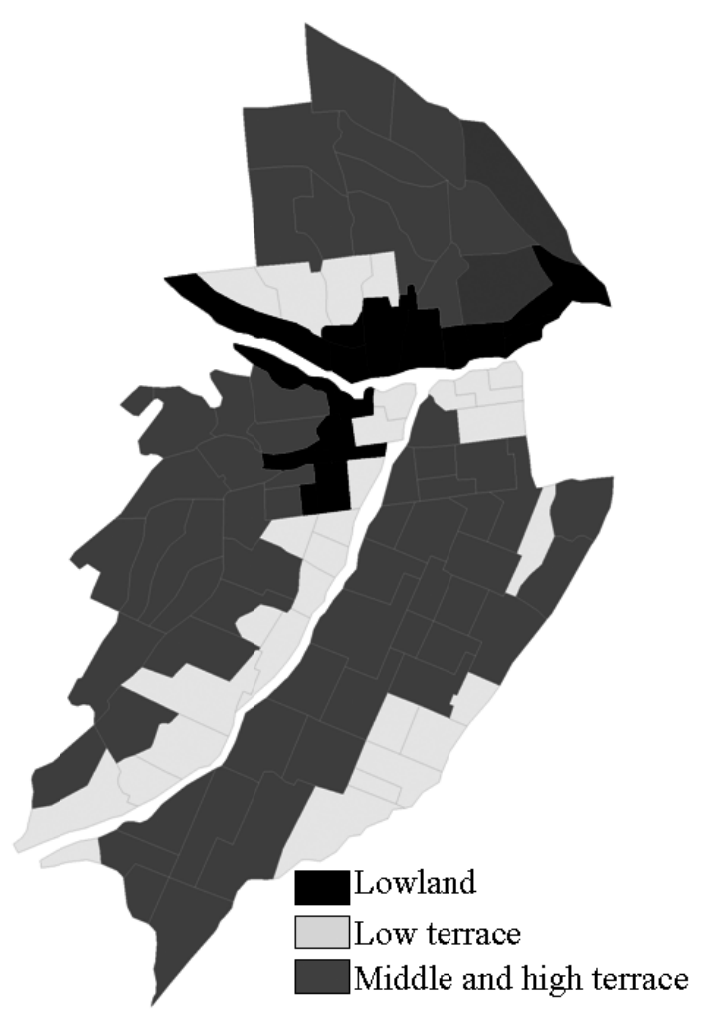

Figure 2. Geographical types of study site 
Approach by satellite data

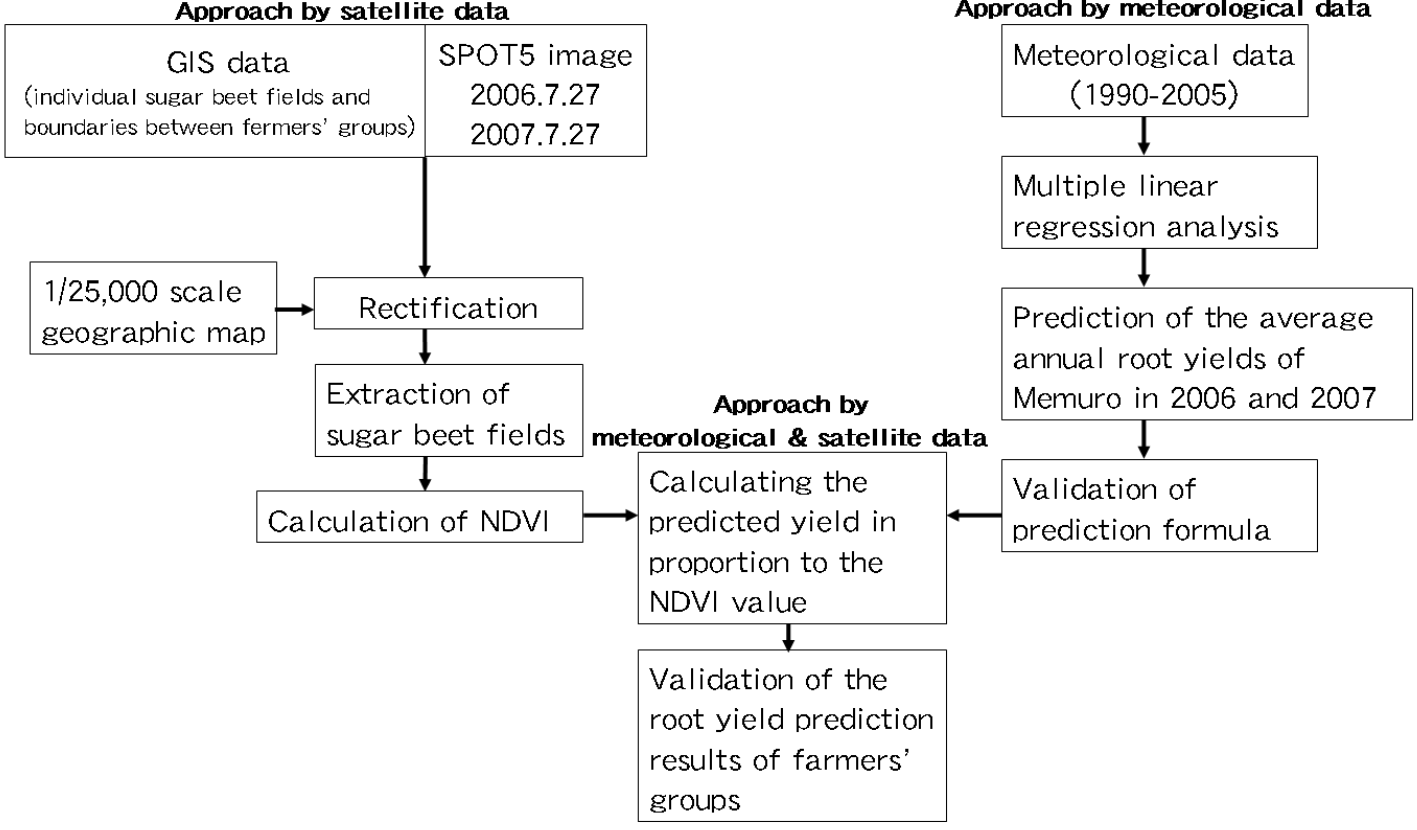

Figure 3. Procedure of image analysis

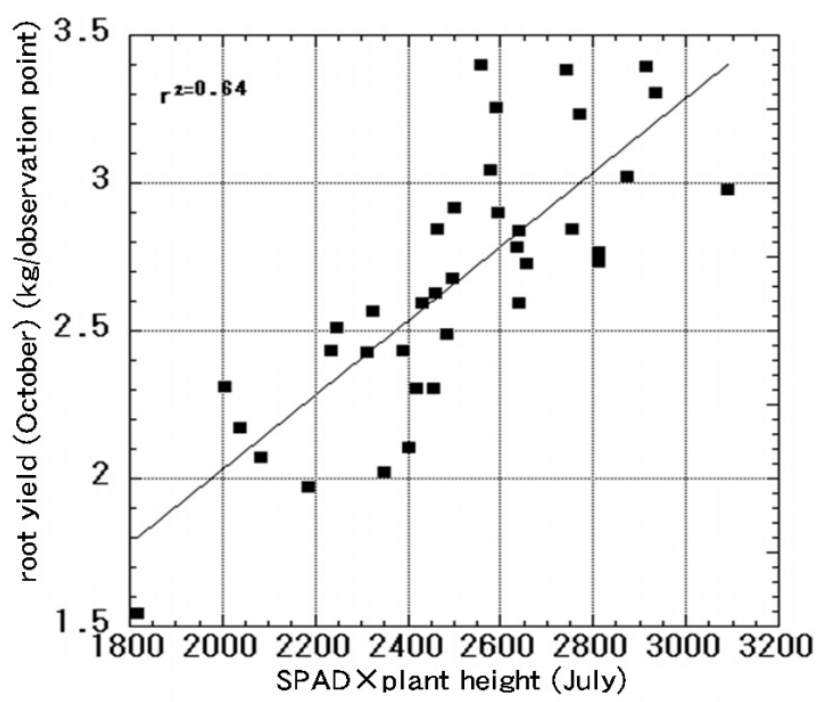

Figure 4. Relationship between SPAD×plant height (July) and root yield (October) 


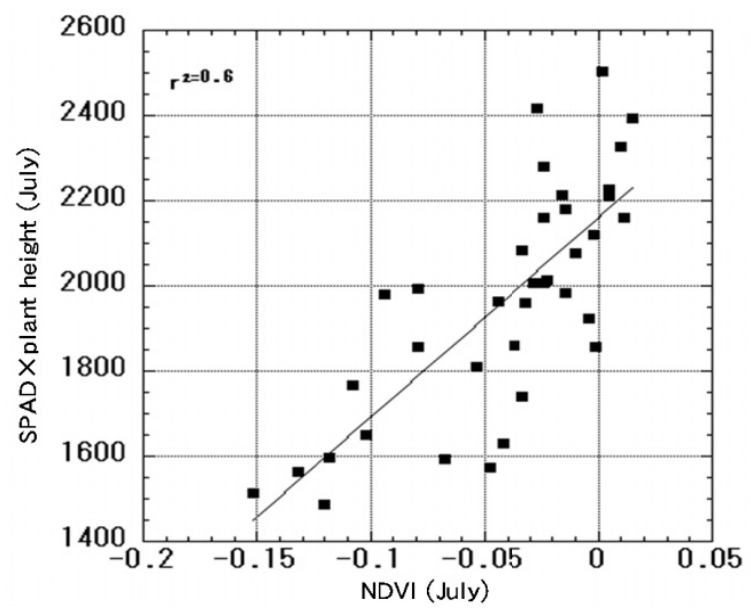

Figure 5. Relationship between SPAD×plant height (July) and NDVI (July)

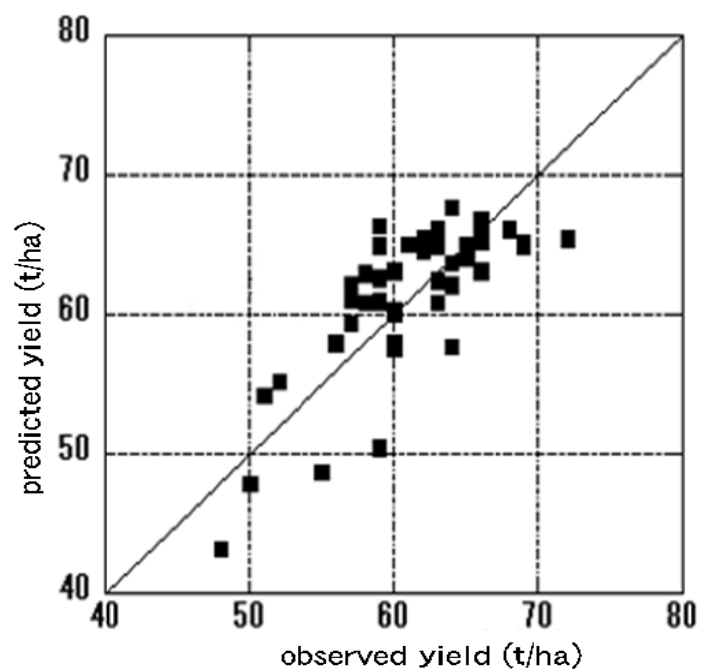

Figure 6. Relationship between predicted yield and observed yield of each farmers' group (2006)

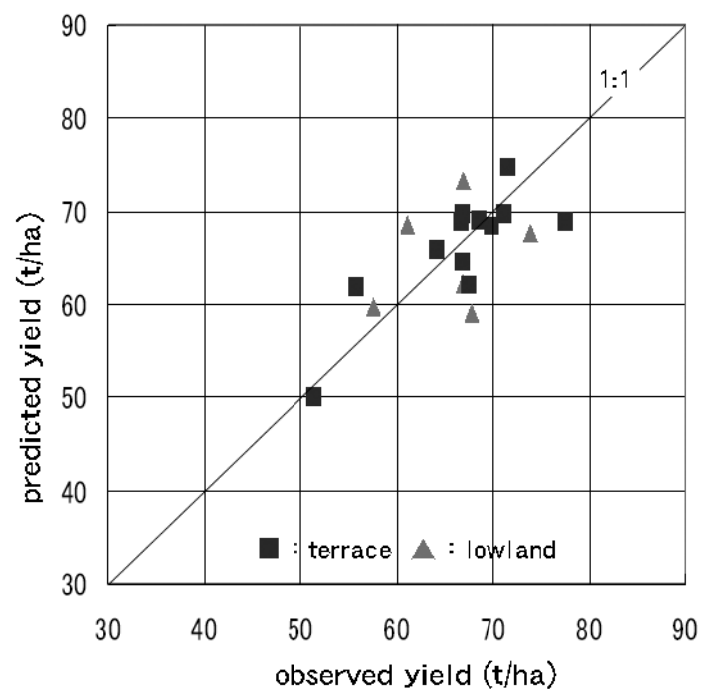

Figure 7. Relationship between predicted yield and observed yield of the field observation points (2007) 


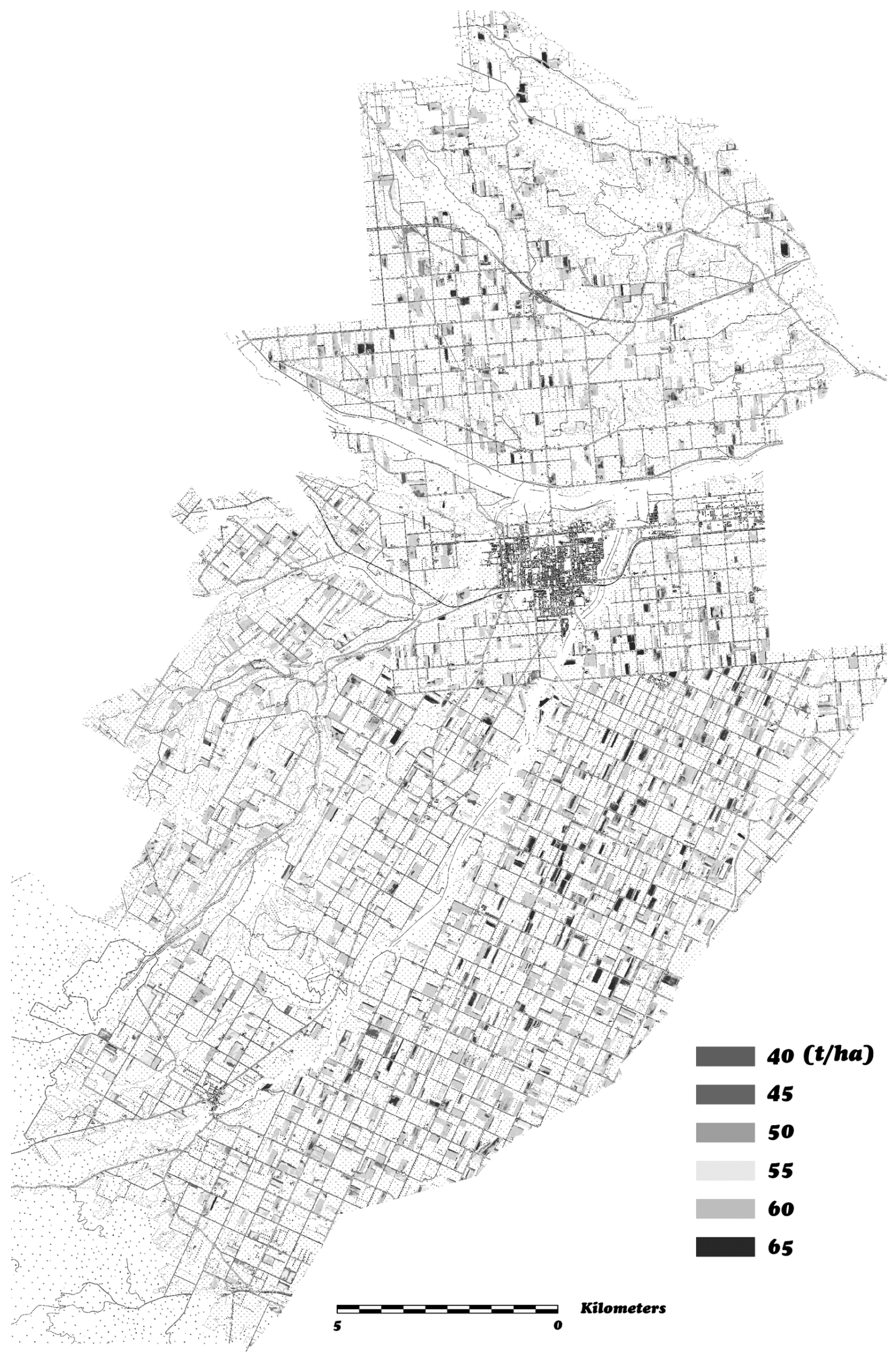

Figure 8. Sugar beet root yield of individual fields in 2006 


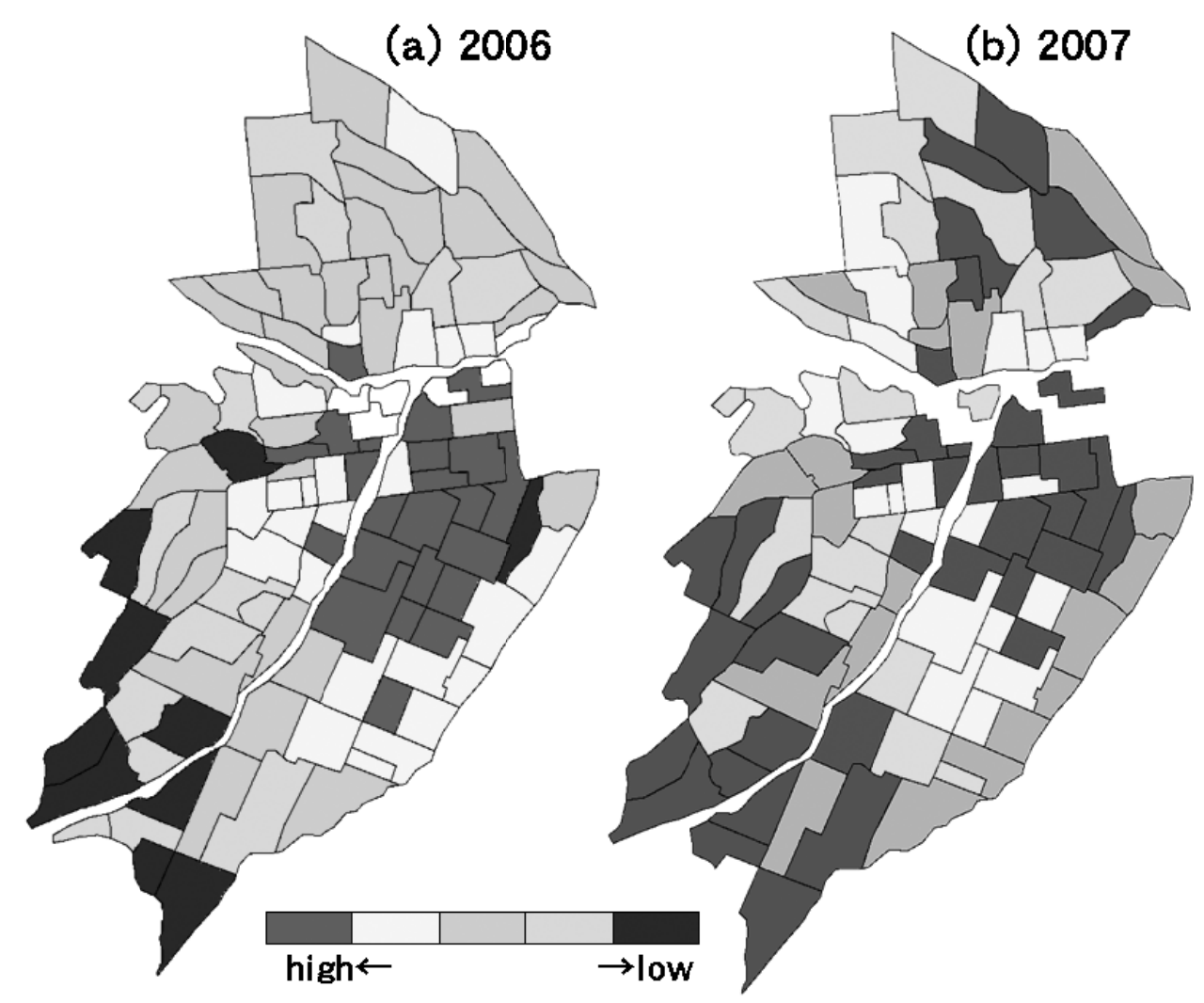

Figure 9. Maps showing root yields of farmers' groups in 2006(a) and 2007(b) 